\title{
Renal lymphangiectasia presenting with hypertension and polycythemia
}

\author{
Mathieu Blanc, MD; Gérard Schmutz, MD; François Belzile, MD; ${ }^{*}$ Robert Sabbagh, MSc, MD
}

"Radiology Department, Faculté de Médecine et des Science de la Santé de l'Université de Sherbrooke, Centre Hospitalier de l'Université de Sherbrooke (CHUS), Sherbrooke, QC; 'Surgery Department, Division of Urology, Faculté de Médecine et des Science de la Santé de l'Université de Sherbrooke, Centre Hospitalier de l'Université de Sherbrooke (CHUS), Sherbrooke, QC

Cite as: Can Urol Assoc J 2014;8(1-2):e163-6. http://dx.doi.org/10.5489/cuaj.1596 Published online March 11, 2014.

\section{Abstract}

We report a very rare case of renal lymphangiectasia, an accumulation of lymph in the renal lymphatic system secondary to obstruction. Our patient presented to his family doctor for an annual check-up which resulted with high blood pressure and polycythemia. An ultrasound was performed and revealed a large right perirenal collection. A year later, a controlled abdominal computed tomography scan showed a progression and compression of perirenal collection on the right kidney, as well as apparition of a left perirenal collection. Percutaneous drainage of both collections was unsuccessful. Laparoscopy-guided marsupialisation was performed and successful. Blood pressure lowered to normal range without medication. The patient's hemoglobin level decreased within normal range after 3 additional phlebotomies postoperatively.

\section{Introduction}

Renal lymphangiectasia is a rare benign disease, which is usually asymptomatic. ${ }^{1}$ It is sometimes associated with hypertension and rarely with polycythemia; there are only 4 reported cases. ${ }^{2-5}$ We present a case of renal lymphangiectasia associated with both hypertension and polycythemia.

\section{Case report}

A 58-year-old asymptomatic male presented with high blood pressure (180/90 $\mathrm{mmHg}$ ), polycythemia (hemoglobin and hematocrit levels at $213 \mathrm{~g} / \mathrm{L}$ and 0.63 , respectively) and fatigue at his annual check-up. He is an active smoker and his medical history was unremarkable. He was started on amlodipine for hypertension. As for his polycythemia, the V617F mutation in the JAK2 gene was negative and therefore polycythemia vera was ruled out. A workup for secondary causes of polycythemia was also negative, except for mild chronic obstructive pulmonary disease. Known mutations for hereditary hemochromatosis were negative. His blood smear was normal. Serum creatinin, erythropoietin and renin levels, as well as the rest of the laboratory tests, were within normal limits.

An abdominal ultrasound was performed for hypertension workup and showed a unilateral right perinephric anechoic collection with multiple septa (Fig. 1a). Further imaging with an abdominal computed tomography (CT) scan showed water-density right perinephric collection with lobulated contours extending to the renal hilum and compressing mildly the renal parenchyma. The left kidney was normal without perinephric collection (Fig. 1b). A renal scintigraphy $(99 \mathrm{mTC}$ MAG-3 with captopril) showed normal renal function with no vascular impairment (renal function of $47 \%$ on the right kidney and $53 \%$ on the left). The patient was treated with phlebotomies to temporarily lower his hemoglobin level. A follow-up abdominal CT scan and magnetic resonance study a year later showed an increased right perinephric collection compressing the renal parenchyma and onset of a similar left perinephric water-density collection without any sign of renal compression (Fig. 2a, Fig. 2b, Fig. 2c).

Ultrasound-guided percutaneous drainage was performed bilaterally and drains were left in place (Fig. 3).

A litre of fluid was removed on both sides during the procedure. Fluid cytology revealed numerous lymphocytes. Fluid analysis was unremarkable for protein, triglycerides, cholesterol, amylase, erythropoietin and creatinine levels. Renin levels were $10.8 \mathrm{ng} / \mathrm{L}$ and $53.1 \mathrm{ng} / \mathrm{L}$ on the left and on the right side, respectively. A biopsy of the outer membrane of the left collection showed lymphoid tissue. Within 10 days of drainage, hemoglobin and blood pressure decreased to normal levels from $188 \mathrm{~g} / \mathrm{L}$ to $156 \mathrm{~g} / \mathrm{L}$ and from $140 / 83 \mathrm{mmHg}$ to $117 / 73 \mathrm{mmHg}$, respectively. Drains were removed 4 days later because of excessive drainage 


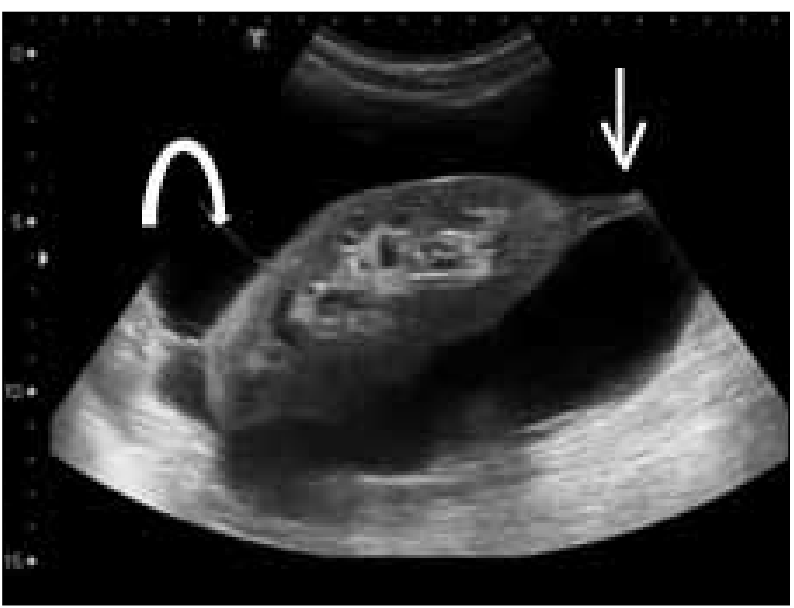

Fig. 1a. Ultrasound imaging - right perinephric anechoic collection with multiple septa (arrows).

( $>1.5 \mathrm{~L} /$ day) that led to dehydration, electrolyte imbalance and mild acute renal failure. A week later, perirenal fluid re-accumulated to pre-drainage level, as noted on repeat CT (Fig. 4). Hemoglobin and blood pressure rose to preprocedure levels.

A laparoscopic bilateral marsupialization was then performed (Fig. 5a, Fig. 5b). At 15 weeks postoperative, a controlled CT scan did not show any significant perirenal collection (Fig. 6).

His blood pressure dropped to normal levels without medication a few days after surgery. The patient also felt better and had more energy than he did before the surgery. His hemoglobin transiently dropped within normal range, but raised a few weeks later $(181 \mathrm{~g} / \mathrm{L})$, so he required 3 phlebotomies on during a 5 -month period $(160 \mathrm{~g} / \mathrm{L})$. No further phlebotomies were required 4 months after the patient quit smoking.

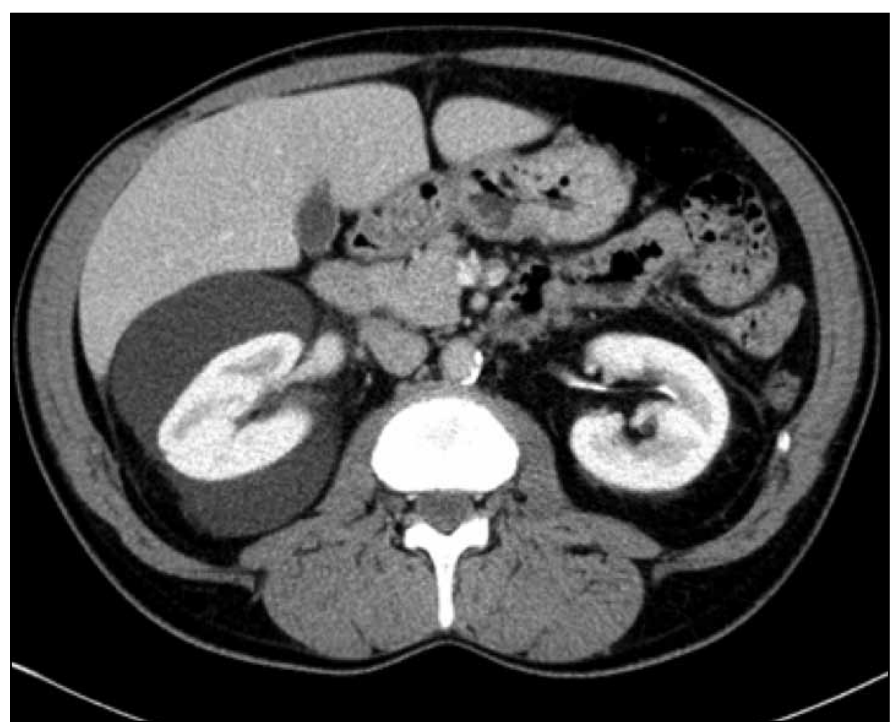

Fig. 1b. A computed tomography scan image showing water-density right perinephric collection with lobulated contours extending to the renal hilum and compressing mildly the renal parenchyma. The left kidney was normal without perinephric collection.

\section{Discussion}

Renal lymphangiectasia is a rare disorder; there are about 50 reported cases. ${ }^{1}$ It is usually bilateral and asymptomatic, and unrelated to age or gender. ${ }^{6,7}$ When symptomatic, it may be associated with abdominal/flank pain, hematuria, proteinuria, abdominal distension/mass, pleural effusion, weight loss, fatigue, renal failure, hypertension or polycythemia. ${ }^{1}$ Familial occurrence has been described. ${ }^{8,9}$ Its pathogenesis remains unknown, but it is hypothesized to result from developmental malformation of the renal lymphatic tissues leading to obstruction and accumulation of lymph in the parenchyma, the subcapsular region and the hilum. ${ }^{8}$ Renal biopsy reveals lymphangiectasis and/or lymphatic vessels increases in number in the medulla, cortex, hilum and

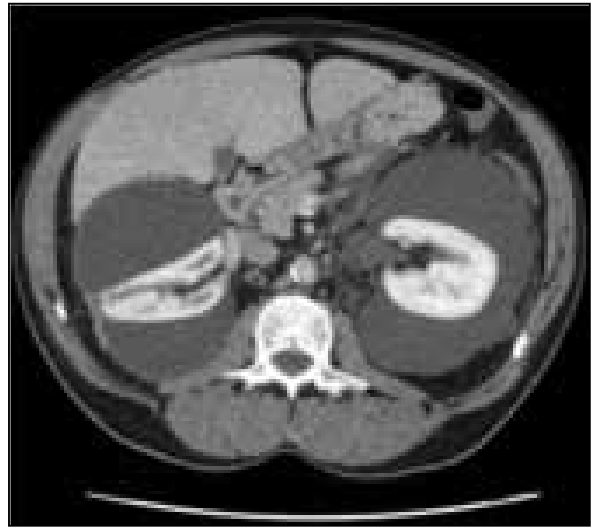

Fig. 2a. A computed tomography scan image a year later - increased right perinephric collection compressing the renal parenchyma and onset of a similar left perinephric water-density collection.

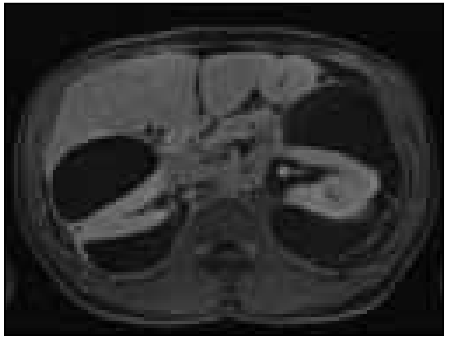

Fig. 2 b. Renal magnetic resonance contrast-enhanced T1-weighted axial image showing bilateral peri-nephric collections with thin peripheral wall enhancement.

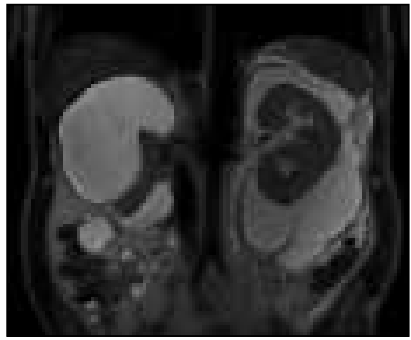

Fig. 2c. Renal magnetic resonance T2-weighted coronal image showing multiloculated high-signal collections. 


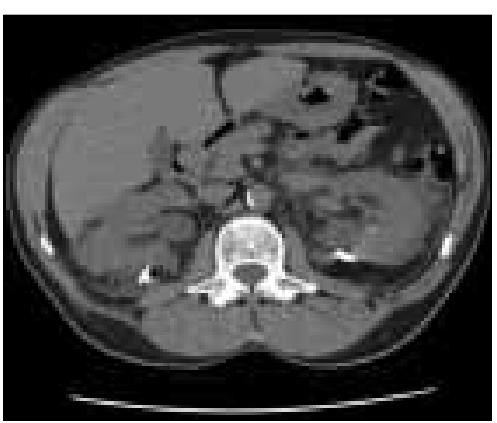

Fig. 3. A computed tomography scan immediately post-drainage with bilateral drains left in place.

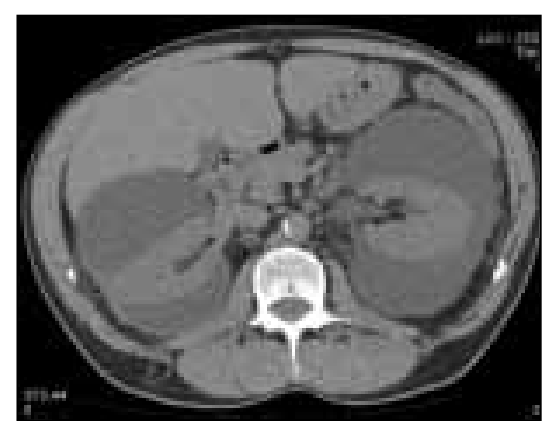

Fig. 4. A computed tomography scan a week post drains removal. Bilateral perirenal fluid re-accumulation to pre-drainage level

and perinephric collection aspirate. Ischemia from renal compression was thought to be the mechanism underlying polycythemia in our case. As surgery transiently decreased hemoglobin levels, there must have been other contributing factors. Our patient was an active smoker and had mild chronic obstructive pulmonary disease, which could have contributed to high hemoglobin levels. ${ }^{18}$ He still required 3 additional phlebotomies after surgery to control his hemoglobin. Smoking cessation was strongly recommended and no further phlebotomies were required 4 months after he quit smoking.

In terms of management, there are no clear perinephric tissues. Diagnosis is usually done on imaging either ultrasound, CT or magnetic resonance imaging, ${ }^{10}$ even though symptoms can precede radiological findings. The radiographic appearance of septated perinephric fluid collections, which can extend around the pelvis and up to retroperitoneal tissues, may lead to a differential diagnosis of hydronephrosis, ${ }^{11}$ hematoma, abscess, lymphoma or polycystic kidney disease. ${ }^{12-15}$ It rarely regresses spontaneously. ${ }^{16}$

Hypertension associated with renal lymphangiectasia is rarely reported. One patient had an ischemic kidney (page kidney) from compression and developed hypertension. ${ }^{17}$ Essential hypertension still accounts for most cases of high blood pressure. In our case, the right perinephric collection was clearly compressing the kidney. It even worsened significantly on controlled CT scans. In addition, our patient's blood pressure normalized rapidly after drainage and definitely after surgery, suggesting hypertension secondary to renal compression. Renin level in the right perinephric collection was 5 times higher than in the left perinephric collection and in the plasma.

Polycythemia associated with renal lymphangiectasia was reported in 4 cases..$^{2-5}$ Our patient presented erythropoietin levels within normal range, measured from serum guidelines as to when conservative management, percutaneous drainage or surgery should be used. It seems, however, that marsupialization is preferred. ${ }^{7}$ Sclerotherapy is a promising treatment. ${ }^{19,20}$

\section{Conclusion}

Renal lymphangiectasia remains an elusive disorder as most of the knowledge comes from case reports, given its rare occurrence. We presented one of the rare cases of renal lymphangiectasia associated with both hypertension and polycythemia, where high blood pressure resolved shortly after laparoscopic marsupialization and polycythemia resolved after smoking cessation.

Competing interests: Dr. Blanc, Dr. Schmutz, Dr. Belzile and Dr. Sabbagh all declare no competing financial or personal interests.

This paper has been peer-reviewed.

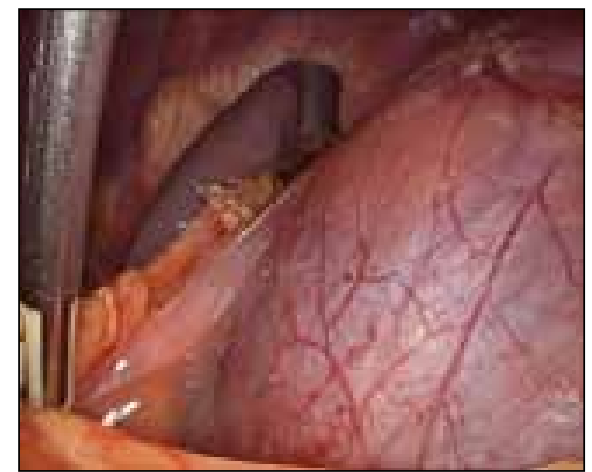

Fig. 5a. Bulging Gerota's fascia around left perirenal collection.

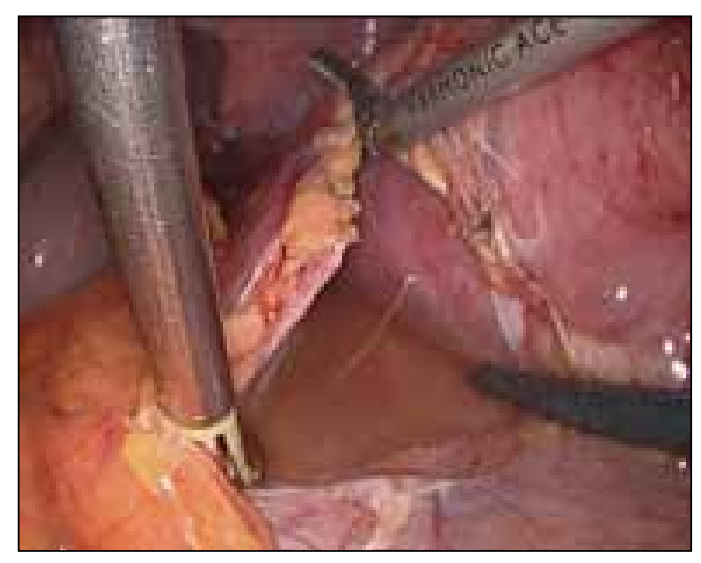

Fig. 5b. Pierced membrane with lymph collection inside. 
Sabbagh et al.

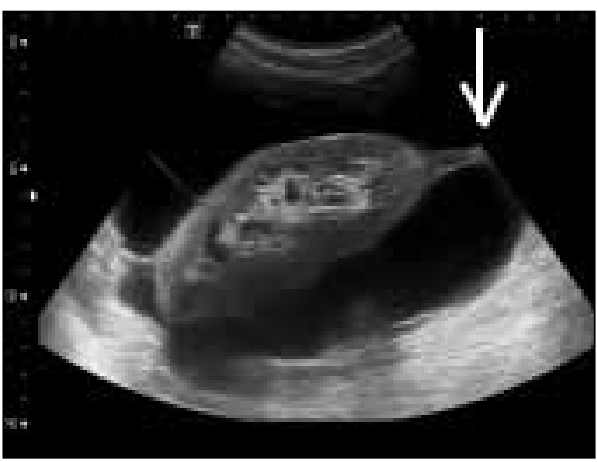

Fig. 5c. Thick septum (straight arrow) on ultrasound.

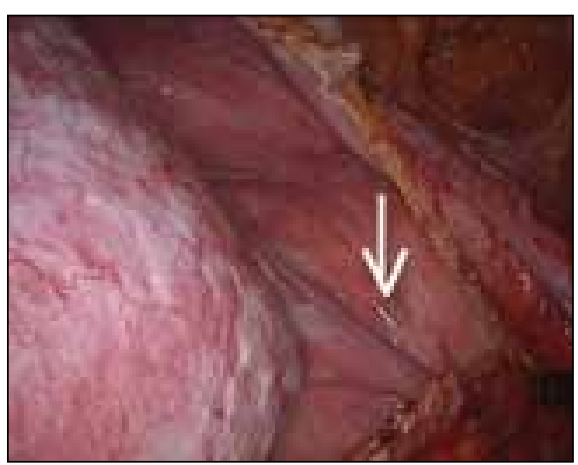

Fig. $5 d$. Thick septum at surgery (straight arrow).

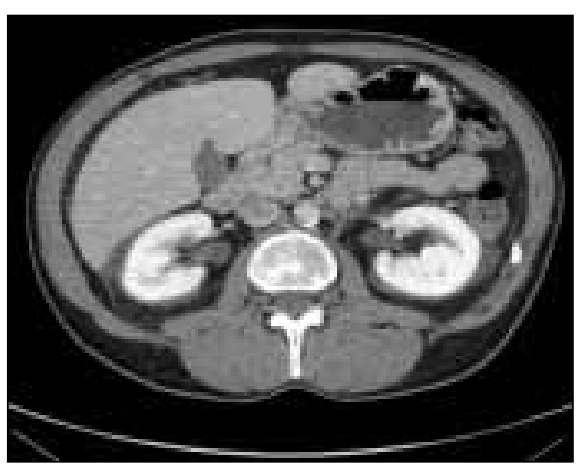

Fig. 6. A computed tomography scan 15 weeks after surgery.

\section{References}

1. Upreti L, Dev A, Kumar Puri S. Imaging in renal lymphangiectasia: Report of two cases and review of literature. Clin Radiol 2008;63:1057-62. http://dx.doi.org/10.1016/i.crad.2007.12.013

2. Burton IE, Sambrook P, McWilliam L. Secondary polycythemia associated with bilateral renal lymphocoeles. Postgrad Med J 1994;70:515-7. http://dx.doi.org/10.1136/pgmi.70.825.515

3. Viglietti D, Sverzut JM, Peraldi MN. Perirenal fluid collections and monoclonal gammopathy. Nephrol Dial Transplant 2012;27:448-9. http://dx.doi.org/10.1093/ndt/grt433. Epub 2011 Aug 2.

4. Shaheen M, Hilgarth KA, Hawes D, et al. A Mexican man with "too much blood." Lancet 2003;362:806. http://dx.doi.org/10.1016/S0140-6736(03) 14291-2

5. Bazari H, Attar EC, Dahl DM, et al. Case records of the Massachussetts General Hospital. Case 23-2010. A 49-year-old man with erythrocytosis, perinephric fluid collections, and renal failure. N Engl J Med 2010;363:463-75. http://dx.doi.org/10.1056/NEJMcpc1004086

6. Haddad MC, Hawary MM, Khoury NJ, et al. Radiology of perinephric fluid collections. Clin Radiol 2002:57:339-46. http://dx.doi.org/10.1053/crad.2001.0854

7. Wadhwa $P$, Kumar $A$, Sharma $S$, et al. Renal lymphangiomatosis: Imaging and management of a rare renal anomaly. Int Urol Nephrol 2007;39:365-8. http://dx.doi.org/10.1007/s1 1255-006-9002-z

8. Antonopoulos $P$, Charalampopoulos $G$, Constantinidis $F$, et al. Familial renal retroperitoneal lymphangiomatosis: personal experience and review of literature. JBR-BTR 2010:93:258-61.

9. Meredith WT, Levine E, Ahlstrom NG, et al. Exacerbation of familial renal lymphangiomatosis during pregnancy. AIR 1988;151:965-6. http://dx.doi.org/10.2214/air.151.5.965

10. Pianezza ML, Mokhtassi A, Wu L, et al. Case report: renal lymphangiectasia. Can J Urol 2006; 13:3204-7.

11. Sarikaya B, Akturk Y, Bekar U, et al. Bilateral renal lymphangiomatosis mimicking hydronephrosis: multidetector CT urographic findings. Abdom Imaging 2006;31:732-4. http://dx.doi.org/10.1007/ s00261-005-8014-y
12. Kocaoglu M, Bulakbasi N, llica T, et al. MRI findings of renal lymphangiectasia. J Magn Reson Imaging 2005;22:681-3. http://dx.doi.org/10.1002/imri.20437

13. Mani NBS, Sodhi KS, Singh P, et al. Renal lymphangiomatosis: A rare cause of bilateral nephromegaly. Australas Radiol 2003;47:184-7. http://dx.doi.org/10.1046/i.0004-8461.2003.01149.x

14. Riehl J, Schmitt H, Schafer L, et al. Retroperitoneal lymphangiectasia associated with bilateral renal vein thrombosis. Nephrol Dial Transplant 1997;12:1701-3. http://dx.doi.org/10.1093/ndt/12.8.1701

15. Ozmen $M$, Deren 0 , Akata $D$, et al. Renal lymphangiomatosis during pregnancy: Management with percutaneous drainage. Eur Radiol 2001;11:37-40. http://dx.doi.org/10.1007/s003300000550

16. Llorente JG, Garcia AD, Sacristan JS, et al. Renal lymphangiectasia: Radiologic diagnosis and evolution. Abdom Imaging 2002;27:637-9. htrp://dx.doi.org/10.1007/s00261-001-0147-z

17. Schwarz A, Lenz T, Klaen R, et al. Hygroma renale: Pararenal lymphatic cysts associated with renindependent hypertension (Page kidney). Case report on bilateral cysts and successful therapy by marsupialization. J Urol 1993;150:953-7.

18. Smith JR, Landaw SA. Smoker's polycythemia. N Engl J Med 1978;298:6-10. http://dx.doi. org/10.1056/NEJM197801052980102

19. Valerio $M$, Meuwly JY, Tawadros $C$, et al. Percutaneous drainage and sclerotherapy as definitive treatment of renal lymphangiomatosis. Can Urol Assoc J 2012;6:E3-E7.

20. Bano S, Yadav SN, Chaturvedi S, et al. Retroperitoneal lymphangiectasia: Radiologic appearances, complications and management alternatives: a case report. Abdom Imaging 2010;35:372-5. http://dx.doi. $\operatorname{org} / 10.1007 / \mathrm{s} 00261-009-9528-5$

Correspondence: Dr. Robert Sabbagh, Associate Professor, Division of Urology, Faculty of Medicine and Health Sciences, 3001, 12e avenue Nord, Sherbrooke, QC JIH 5N4; fax: 819-820-6411; robert.sabbagh@USherbrooke.ca 